\title{
HEALTH IMPACT ASSESSMENT IN NEW ZEALAND
}

\section{Barbara Langford \\ Public Health Advisory Committee \\ New Zealand}

New Zealand has a history of the assessment of projects for their potential impact on health in the context of the New Zealand Resource Management Act 1991. Health impact assessment (HIA) at policy level is very new, and focuses on high-level policies from outside the health sector. It has largely developed since the Public Health Advisory Committee published its guidance to policy makers in $2004^{1}$, followed by intensive promotion, capacity building and support to agencies undertaking HIA. (The Public Health Advisory Committee was established under the New Zealand Health and Disability Act 2000 to provide the Minister of Health with independent public health advice.) It is 'work in progress' and, as such, the Committee has not yet published any results. The Committee is also collaborating with the Wellington School of Medicine and Health Sciences, and Quigley and Watts Ltd, with advice and support from Deakin University, to deliver HIA training and to support agencies that undertake an HIA. The Committee will review uptake in the second quarter of 2006, the reasons for agencies choosing (or not choosing) to undertake HIA and what changed as a result.

The momentum for applying HIA across sectors has been assisted by a number of recent legislative and policy changes that have increased interest from agencies that recognise HIA as a tool to help them meet their legislative requirements. For example, HIA assists the transport sector in meeting the new public health objectives of the New Zealand Transport Strategy. ${ }^{2}$ Local governments are seeing its value in assisting them to address the requirement of the Local Government Act 2002, 'to promote the social, cultural, environmental and economic wellbeing' of their communities, and in developing the community outcomes required by the Act. It also sits well with other government policy directions such as the encouragement of 'whole of government' approaches, reducing inequalities, and sustainable development, and it provides a vehicle for community consultation and collaboration across sectors.

\section{ESSENTIAL INGREDIENTS FOR SUCCESS}

The HIA work in New Zealand has reinforced international findings about the essential ingredients for successful HIAs:

- Public health expertise and specific HIA advice is crucial, particularly in the planning stages of an HIA and before capacity for HIA has been built in an agency.
- Although ideally applied early in the policy development process, the policy options need to be sufficiently well developed, with clear expected outcomes.

- A degree of public health understanding in the policy agency is needed, including knowledge of the wider determinants of health. The term 'wellbeing' resonates in agencies outside health.

- Collaboration across sectors is important, especially at the appraisal stage of the process.

- A dedicated HIA support unit is needed to promote, encourage and support HIA.

\section{ISSUES FOR HIA IN NEW ZEALAND}

The sustainability of HIA in New Zealand will depend on support at central government level, accessibility of funding streams, building an HIA history, and on building capacity in the public health and other sectors. HIA is gaining momentum in the regions, with public health services and local government working together to undertake HIAs on urban growth strategies and plans, on regional land transport strategies and urban design models. While this work has been dependent upon public health leadership and funding, it is gaining momentum through capacity building in the local government and public health sectors.

At the central government level, HIA has been developing more slowly. Some government departments are considering HIA, and an HIA on the building standards for New Zealand is being planned for next year. HIA at this level will be dependent upon political support and a greater understanding by other sectors of the potential impact that their policies have on health and wellbeing.

\section{REFERENCES}

1. Public Health Advisory Committee. A guide to health impact assessment: a policy tool for New Zealand. Wellington, New Zealand Government, 2004. www.nhc.govt.nz/PHAC/ publications/guidetohia.pdf

2. New Zealand Government, New Zealand Transport Strategy, 2002. Available from www.beehive.govt.nz/nzts/home.cfm, accessed 8 November 2005. 